\title{
Fontan modification with a Y-graft
}

\author{
Aditya K. Kaza, MD
}

See related article on pages 239-45.

The well-written article by Hunt Martin and colleagues ${ }^{1}$ in this issue of the Journal describes a single-institution experience with the Y-graft modification for Fontan completion. The cavopulmonary connection has evolved significantly since it was first described by Fontan and coworkers. ${ }^{2}$ In this particular case, Martin and colleagues aim to translate the superior hemodynamic and hepatic blood flow distribution seen in computational modeling with the use of bifurcated Fontan grafts. ${ }^{3}$ The fundamental premise for using this type of Fontan modification is that this type of arrangement is superior to the pure energy conservation afforded by offsetting the Glenn and Fontan flows. These benefits are still theoretic, and there is no demonstration in the article that the computer modeling scenario was duplicated in the clinical outcomes of these children. Martin and colleagues, however, have been able to demonstrate technical feasibility of using these bifurcated grafts with excellent safety and hemodynamic results. This is an extremely important area of investigation to optimize hemodynamics and flow distributions in patients undergoing completion Fontan operations. Other groups ${ }^{4}$ have also used computational modeling to tout the beneficial effects of bifurcated Glenn and Fontan pathways or the "optiflow" configuration.

Two of the authors of this article have published previous work ${ }^{3}$ related to the computational modeling and preclinical evaluation, examining the impact of this Fontan modification on hepatic blood flow distribution. They have successfully shown that in the modeling scenario, there is more symmetric hepatic blood flow distribution. This article shows the nice systematic evolution of this theoretic

concept to clinical translation. They have now shown the clinical feasibility of this modified cavopulmonary connection. There are some concerning outcomes which need to be rectified before widespread recommendation or use, especially the avoidance of thrombus formation in one of the limbs. In addition, there needs to be long-term follow up with quantification of arteriovenous malformation in the pulmonary vasculature and general clinical outcomes and the presence or absence of other signs of Fontan failure, such as plastic bronchitis or protein-losing enteropathy. Another potential benefit of this bifurcated graft technique is to customize the diameter of limbs (and as a result, flow) to each lung according to the degree of arteriovenous malformation noted on pre-Fontan studies. Long-term flow and hemodynamic data would further convince clinicians to adopt this Fontan modification technique. The results of this early experience with this Y-graft Fontan modification are encouraging, and it is to hoped that Martin and colleagues will publish more follow-up data to determine whether there are any hemodynamic and functional advantages related to this modification.

\section{References}

1. Hunt Martin M, Feinstein JA, Chan FP, Marsden AL, Yang W, Mohan Reddy VM. Technical feasibility and intermediate outcomes of using a handcrafted, areapreserving, bifurcated Y-graft modification of the Fontan procedure. J Thorac Cardiovasc Surg. 2015; 149:239-45.

2. Fontan F, Mounicot FB, Baudet E, Simonneau J, Gordo J, Gouffrant JM. "Correction" of tricuspid atresia. 2 cases "corrected" using a new surgical technic [in French]. Ann Chir Thorac Cardiovasc. 1972;10:39-47.

3. Yang W, Feinstein JA, Shadden SC, Vignon-Clemntel IE, Marsden AL. Optimization of a Y-graft design for improved hepatic flow distribution in the Fontan circulation. J Biomech Eng. 2013; 135:011002.

4. Slesnick TC, Yoganathan AP. Computational modeling of Fontan physiology: at the crossroads of pediatric cardiology and biomedical engineering. Int J Cardiovasc Imaging. 2014;30:1073-84.

From the Department of Cardiac Surgery, Boston Children's Hospital, Boston, Mass. Disclosures: The author has nothing to disclose with regard to commercial support. Received for publication Sept 11, 2014; accepted for publication Sept 11 2014; available ahead of print Oct 5, 2014.

Address for reprints: Aditya K. Kaza, MD, Department of Cardiac Surgery, Boston Children's Hospital, 300 Longwood Ave, Bader 273, Boston, MA 02115 (E-mail: Aditya.kaza@cardio.chboston.org).

J Thorac Cardiovasc Surg 2015;149:246

$0022-5223 / \$ 36.00$

Copyright (C) 2015 by The American Association for Thoracic Surgery

http://dx.doi.org/10.1016/j.jtcvs.2014.09.015 